\title{
Histórias de vida de professores: o caso da educação profissional
}

\author{
Suzana Burnier \\ Regina Mara Ribeiro Cruz \\ Marina Nunes Durães \\ Mônica Lana Paz \\ Adriana Netto Silva \\ Ivone Maria Mendes Silva
}

Centro Federal de Educação Tecnológica de Minas Gerais

\section{Introdução}

Tendo como referência o pensamento de autores como Agnes Heller (1992), segundo quem o sujeito é, simultaneamente, ser genérico e ser particular, pretendemos explorar as histórias de vida de professores da educação profissional, tomando-os como seres concretos, lançados em determinada cotidianeidade ao nascer, cotidianeidade esta na qual o sujeito é, a um só tempo, produto e produtor.

Investigamos, em pesquisa desenvolvida no Centro Federal de Educação Tecnológica de Minas Gerais (CEFET-MG), os processos de construção das identidades profissionais de 20 professores da educação profissional, segmento pouco presente nos estudos acadêmicos até então. Dialogando com docentes que atuam em escolas privadas ou do Sistema $\mathrm{S},{ }^{1}$ ou

${ }^{1} \mathrm{O}$ chamado Sistema "S" é formado por organizações criadas pelos setores produtivos (indústria, comércio, agricultura, transportes e cooperativas) com a finalidade de qualificar e promover o bem-estar social de seus trabalhadores, a saber: Serviço Nacional também em escolas públicas (federais, estaduais e municipais), e ainda em instituições filantrópicas, interessa-nos conhecer como e por que profissionais de diversas áreas de formação técnica (engenheiros, administradores, economistas, contabilistas, químicos,

de Aprendizagem Comercial (SENAC) e educação profissional para trabalhadores do setor de comércio e serviços; Serviço Social do Comércio (SESC), promoção da qualidade de vida dos trabalhadores do setor de comércio e serviços; Serviço Nacional de Aprendizagem Rural (SENAR) e educação profissional para trabalhadores rurais; Serviço Nacional de Aprendizagem em Transportes (SENAT) e educação profissional para trabalhadores do setor de transportes; Serviço Social de Transportes (SEST) e promoção da qualidade de vida dos trabalhadores do setor dos transportes; Serviço Brasileiro de Apoio às Pequenas e Médias Empresas (SEBRAE) e programas de apoio ao desenvolvimento de pequenas e médias empresas; Serviço Nacional de Aprendizagem do Cooperativismo (SESCOOP) e aprimoramento e desenvolvimento das cooperativas e capacitação profissional dos cooperados para exercerem funções técnicas e administrativas. Disponível em: <http://www.senai.br/br/ParaVoce/faq.aspx >. 
enfermeiros, entre outros) se encontram, em algum momento de suas trajetórias de vida, exercendo o ofício da docência.

Colocamo-nos as questões: como se dá sua entrada no magistério? Que fator ou fatores pesaram positiva ou negativamente para a sua decisão? Que marcas, modos, projetos e expectativas de vida os distinguem, e como podem, de alguma forma, tê-los levado a aproximar-se do magistério? Que elementos emergem nas relações construídas no interior da escola e contribuem para que lá permaneçam? O fato de terem, antes da docência, vivenciado o mercado de trabalho como profissionais de outras áreas técnicas teria alguma influência sobre suas representações e projetos profissionais? Partindo da hipótese de que sim, esses docentes apresentariam representações sobre o ofício do magistério distintas daquelas encontradas entre seus colegas da educação básica.

Para responder a essas questões, definiram-se os seguintes objetivos de pesquisa: a) analisar as representações acerca do ofício por professores da educação profissional; b) investigar suas histórias de vida e os fatores que contribuíram para suas escolhas relativas à carreira: ingresso, permanência, abandono; c) analisar as concepções, subjacentes ou explícitas, de educação de uma maneira geral e de educação profissional em particular, que orientam as práticas desses professores, e apontar pistas para a formação de professores da educação profissional que levem em consideração as experiências desses docentes, suas demandas, necessidades e potencialidades.

Focando nossa atenção no indivíduo - resultado tanto das relações sociais quanto de sua subjetividade - a opção metodológica da pesquisa direcionou-se para uma abordagem centrada nas narrativas de história de vida dos entrevistados, uma vez que assumimos, com Dubar (1997), que os complexos processos identitários contemporâneos implicam uma articulação entre o processo relacional do espaço profissional e a trajetória biográfica dos profissionais, e possibilita inúmeras posturas ante o campo profissional.

Durante a coleta dos depoimentos, foram observadas três dimensões: as experiências do entrevista- do ao longo de sua vida; as circunstâncias que ensejaram seu ingresso no magistério e as situações aí vivenciadas e que lá o mantêm.

\section{Perspectivas teórico-metodológicas: histórias de vida e o campo da educação}

As narrativas ou entrevistas de história de vida oferecem o marco teórico-metodológico adotado ao investigarmos os percursos pessoais e profissionais de docentes da educação profissional. Além da adequação desse tipo de abordagem ante a problemática e o objeto de estudo em questão, reconhecemos tratarse de um recurso de investigação científica com prolífica tradição nas ciências humanas, especialmente nos campos da sociologia, psicologia e história. $\mathrm{Na}$ área da educação, o uso cada vez mais disseminado das histórias de vida tem contribuído para uma melhor compreensão da condição docente, na medida em que renova as teorizações e os dispositivos de pesquisa e formação profissional.

Na literatura internacional, os trabalhos de autores como António Nóvoa (1992), Michäel Huberman (1992), Claude Dubar (1997), Ivor F. Goodson (1992), Pierre Dominicé (1990), Franco Ferrarotti (1988), entre outros, ilustram bem essa tendência, oferecendo forte respaldo ao emprego da abordagem biográfica e das histórias de vida na pesquisa educacional. Com análises ricas, predominantemente voltadas à educação básica, e marcados pela consistência metodológica, tais trabalhos despertaram interesse, influenciaram a configuração da produção intelectual brasileira e, para muitos pesquisadores, acabaram tornando-se uma referência.

Todavia, segundo Nunes e Cunha (2005), tem-se considerado que, somente a partir da década de 1990, após o advento das discussões acerca do saber docente e do ofício de professor, anuncia-se no Brasil um período de proliferação dos métodos biográficos, com diversos teóricos e pesquisadores apostando em sua qualidade e valor heurístico. De fato, ao analisarmos as tendências atuais da pesquisa sobre docência e as preocupações de investigação, ação e formação nelas 
embutidas, podemos perceber o crescimento dos estudos que focalizam a vida ou desenvolvimento pessoal dos professores, carreiras e percursos profissionais, profissionalização e identidades docentes, ciclos de vida e experiência docente, memórias, relação entre o universo profissional e outros universos socioculturais (André, 1997). As feições assumidas por esses estudos sugerem a adoção de um tipo de enfoque que alimenta o interesse pelo sujeito professor, e não apenas por suas práticas de ensino ou competências técnicas, e direciona o olhar para a importância de se compreenderem as representações e valores construídos pelo professor acerca da profissão docente, na interface entre as dimensões pessoal e profissional.

Numa obra pioneira, hoje considerada clássica, Vida de professores (Nóvoa, 1992), alguns dos autores citados expõem os resultados de suas pesquisas e discutem as especificidades, os desafios e as possibilidades do trabalho com histórias de vidas. Como alerta Nóvoa (1992), na seção dedicada a considerações sobre sistematização metodológica, o que chama a atenção e requer uma problematização atenta no âmbito da pesquisa em educação nessa nova etapa é "a profusão de interesses, de concepções e de estratégias que se acomodam sob a designação de histórias de vida. A situação complica-se consideravelmente quando se menciona a heterogeneidade de modos de trabalho e de técnicas de investigação" (p. 23). O autor conclui que essa diversidade não é, em si, um problema, uma vez que pode ampliar os recursos postos a serviço do trabalho de investigação científica. Em contrapartida, também carregaria a potencialidade de gerar dificuldades e equívocos, caso as construções metodológicas prescindam, como por vezes ocorre, do rigor e do exercício da reflexão ética.

Numa tentativa de sistematização dos tipos de estudos centrados nas histórias de vida de professores, e tomando como base os objetivos e as dimensões que cada um deles privilegia, Nóvoa (1992) propõe uma categorização que agrupa nove tipos de estudos. A variação entre esses tipos depende, por um eixo de análise, de os objetivos subjacentes remeterem à investigação ou formação ou investigação-for- mação, e, por outro eixo, de as dimensões a serem alcançadas referirem-se à pessoa do professor, às práticas dos professores ou à profissão do professor. São nove as combinações possíveis a partir dessas dimensões e objetivos, mas isso não significa que devam ser encaradas como "categorias exclusivas", conforme afirma o autor. ${ }^{2}$

À luz dessa sistematização, assumimos o estudo descrito no presente artigo como sendo de caráter eminentemente investigativo, tomando como referência tanto a pessoa do professor quanto sua profissão e suas práticas, tais como emergem nos discursos proferidos pelos entrevistados. No decurso da pesquisa, tivemos como objetivo focar a atenção sobre os sujeitos e as diversas dimensões de suas trajetórias de vida (lazer, família, lugar de trabalho, grupos de referência etc.), ao mesmo tempo em que indagamos sobre os projetos e valores que orientaram suas escolhas ao longo dos percursos profissionais. Nesse sentido, adotamos como pressuposto teórico o fato de que tais dimensões se encontram interligadas, compondo a rica trama das histórias de vida dos professores, e assim, inscrevendo-as numa materialidade temporal e espacial.

Concordamos com Queiroz (1988) quando define a história de vida como:

[...] o relato de um narrador sobre sua existência através do tempo, tentando reconstituir os acontecimentos que vivenciou e transmitir a experiência que adquiriu. Narrativa linear e individual dos acontecimentos que nele considera significativos, através dela se delineiam as relações

${ }^{2}$ Os nove tipos de estudos seriam aqueles com: 1) Objetivos essencialmente teóricos relacionados com a investigação versus a) pessoa; b) práticas; c) profissão; 2) Objetivos essencialmente práticos relacionados com a formação versus a) pessoa; b) práticas; c) profissão; 3) Objetivos essencialmente emancipatórios relacionados com a investigação-formação versus a) pessoa; b) práticas; c) profissão. Dadas as restrições de espaço neste artigo, limitar-nos-emos a essa rápida menção. Ver detalhes da categorização em Nóvoa (1992, p. 21). 
com os membros de seu grupo, de sua profissão, de sua camada social, de sua sociedade global, que cabe ao pesquisador desvendar. (p. 20)

Ouvimos, portanto, o depoimento de 20 professores de instituições de educação profissional da Região Metropolitana de Belo Horizonte. A seleção de tais docentes procurou atender aos seguintes critérios:

- professores de ambos os sexos. Foram 11 professores e 9 professoras;

- professores com mais e menos tempo de magistério. Nossa intenção inicial era abranger professores em todas as fases do magistério, ouvindo igualmente professores em início, meio e final da carreira docente. $\mathrm{O}$ tempo de magistério dos sujeitos da nossa pesquisa variou entre 2 e 33 anos de docência;

- professores das diversas redes de ensino. Nossos entrevistados lecionavam em escolas da rede pública (federal, estadual e municipal), em escolas particulares e em instituições filantrópicas.

Todos os depoimentos, gravados e filmados, aconteceram nas instalações do CEFET-MG, em espaço previamente preparado para tal. Além dos membros do grupo de pesquisa, também estiveram presente alunos do Programa de Formação de Professores do CEFETMG. Sem conhecer os objetivos da pesquisa, o entrevistado era orientado a falar, por aproximadamente uma hora, sobre sua história de vida, incluindo aspectos de sua vida pessoal e profissional que considerasse relevantes. Depois dessa primeira etapa, chamada de depoimento, os trabalhos estendiam-se por mais uma hora, agora com caráter mais de entrevista, com perguntas dos membros do grupo, estas, sim, direcionadas pelas questões e objetivos da pesquisa. No contexto dessa abordagem, os professores entrevistados tiveram a oportunidade de relembrar fatos passados em suas vidas e refletir sobre aspectos, tais como: "que experiências me marcaram como aluno e de que forma isso repercute em minha visão atual sobre o que é ser um bom professor"; "por que me tornei professor"; "como me tornei o professor que sou", "que valores e perspectivas impregnam minha forma de ensinar". Tais reflexões contribuíram para que identificassem práticas e valores em seu presente que, situados no conjunto da história de vida, desempenham um papel ativo na construção de suas identidades, especialmente a profissional, considerando as condições de existência e os contextos específicos em relação aos quais tais sujeitos puderam estruturar suas experiências. Importa destacar que foi assegurada a todos os depoentes a proteção de sua identidade pessoal em todos os produtos gerados pela pesquisa.

Acreditamos, portanto, que, a partir das possibilidades criadas por esse tipo de metodologia, importantes problematizações e intervenções têm emergido. A própria maneira de pensar o diálogo entre o individual e o contexto sociocultural ganha novos contornos, pois o pesquisador, ao debruçar-se sobre os dados obtidos no contexto das narrativas dos sujeitos, se depara com o desafio de compreender tais histórias não apenas a partir de suas especificidades, mas também levando em conta o que há de "compartilhado" com as histórias de outros sujeitos, conforme demarca André (1997, p. 72). Assim, cada história de vida, ao mesmo tempo em que nos leva a conhecer um percurso ou experiência pessoal, singular, retrata de algum modo o universo social mais amplo, no qual é inscrito esse percurso.

\section{História de vida e construção da identidade docente}

Assumimos aqui, com Agier (2001), Sanchis (1996) e Hall (1999), a noção de identidade como um jogo de processos de identificação ou processos identitários, sempre mutáveis, ainda que referenciados no substrato concreto do campo de possibilidades (Velho, 1994) - múltiplo e diversificado - em que o sujeito seleciona, ativamente, esquemas de ação dentre as várias alternativas que se lhe apresentam. Assinalamos, ainda, o caráter relacional da identidade, em que se manifesta uma tensão permanente entre iden- 
tidades para si e para o outro (manifestadas em atos de pertença e atos de atribuição). Outra importante tensão nos processos identitários surge entre o instituído e o instituinte, em que poderemos encontrar identificações momentâneas em curso, carregadas de contradições, continuidades e rupturas contraditoriamente justapostas, assumidas ou descartadas. Essa tensão aponta para a permanente possibilidade de construção e reconstrução de novos valores, perspectivas e projetos, por processos de reinterpretação ou bricolagem de elementos oriundos de tradições diversas, articulados sob determinados valores que thes conferem lógica e coerência. Não abandonamos a compreensão de que qualquer processo humano exige alguma permanência. Primeiro, porque realidade e representação se articulam na constituição do objeto social, nunca pura representação, nem pura materialidade. Segundo, porque a história se apresenta com suas pregnâncias e permanências, carregando para o presente a tradição - sempre mutável, mas, ainda assim, ponto de partida. Nas palavras de Sanchis (1996):

[...] [os processos de invenção], uma vez "socialmente construídos", pesam de toda a sua "realidade" (relativa e por sua vez moldável) sobre a história em se fazendo. Nesse sentido - enfim! - é verdade que uma identidade social é um projeto, uma estratégia de construção da própria imagem de referência - para si e para os outros. Orientada para o futuro. É verdade que a identidade não é "simplesmente" recebida ou herdada. Nenhum grupo humano é condenado a se reconhecer eternamente referências, interesses ou destinos comuns, simplesmente em nome de um passado ou de um conjunto de traços "naturais" compartilhados. Constantemente ele se auto-identifica criativamente frente a outros e no seio de situações determinadas. Mas é também verdade que este projeto não é resposta arbitrária a tais situações. Ele tem que se haver com forças que o enraízam dinamicamente na espessura do passado. Ele é "pro-jetado" criativamente, mas "a partir de". E estas duas dimensões chamam-se para serem articuladamente reconhecidas. (p. 5)

Dar voz aos professores pelo relato de sua história de vida implica considerar seu percurso pessoal na construção de sentidos para a docência. Conforme afirma Nóvoa (1992, p. 7), "não é possível separar o eu pessoal do eu profissional". Nesse processo de reflexão sobre seu percurso de vida, o indivíduo manifesta sua subjetividade e interpreta suas ações no plano individual e coletivo, na busca de significados para construção de sua identidade profissional. Nesse sentido, o método autobiográfico possibilita ao docente, pelo relato de sua história de vida, revelar seus anseios e expectativas ante a profissão docente e a própria vida.

Em relação à docência, as expectativas são diferenciadas. A imagem que o professor constrói de si mesmo e perante a sociedade faz parte do processo constitutivo de sua identidade profissional. Esse processo está em constante transformação, reconstruindo-se ao longo da vida, de acordo com suas experiências sociais e individuais. A maneira como o docente constrói a sua imagem profissional participa na definição de suas ações com os alunos, de suas relações no cotidiano do trabalho e do desenvolvimento de suas atividades pedagógicas. A construção identitária subsidiará a maneira como o homem se coloca perante o mundo e diante das relações de trabalho (Gatti, 1996).

O sociólogo francês Claude Dubar (1997) enfatiza a identidade humana como construção a um só tempo individual e coletiva, associada ao processo de intervenção dos indivíduos sobre si mesmos e a diversos fatores externos, entre eles as visões de mundo construídas socialmente, de acordo com a cultura em que vivem. Ainda que utilize uma concepção de identidade mais substancialista do que aquela que aqui estamos adotando, queremos resgatar algumas contribuições desse autor, que se dedicou especialmente à questão da identidade profissional.

Dubar destaca o caráter dinâmico da identidade profissional, sempre em mutação em sua relação constante com questões como as taxas de desemprego, os níveis escolares, as origens sociais, as transformações tecnológicas, bem como a transição entre a conclusão dos estudos e a busca de uma atividade no mercado de trabalho. O autor observa que o acesso ao emprego tem um caráter instável, pois afeta o profissional 
de formas distintas, e gera confrontos entre aqueles que adentram na atividade profissional. Esse confronto promoverá o processo de construção da identidade profissional "que constitui não só uma identidade no trabalho, mas também e sobretudo uma projecção de si no futuro, a antecipação de uma trajetória de emprego e o desencadear de uma lógica de aprendizagem, ou melhor, de formação" (Dubar, 1997, p. 114). Nesse contexto, o indivíduo constrói sua identidade profissional criando representações sobre si mesmo e suas funções, interligadas à sua história de vida, formação e profissionalização.

Acerca da profissionalização e suas implicações no processo de construção das identidades, Kaddouri (2005) reforça as idéias até então apresentadas, definindo a profissionalização como um processo em movimento, dinâmico, que se constrói basicamente a partir de três projetos: institucional, coletivo e individual, que estão mutuamente interligados. $\mathrm{O}$ institucional refere-se à busca de normas e valores, como uma expressão do projeto identitário institucional para as pessoas. A profissionalização é caracterizada como coletiva quando reivindicada por um grupo profissional na elaboração de estratégias comuns de transformação da prática. $\mathrm{O}$ autor sugere que o projeto institucional, em parceria com o coletivo/individual, pode acarretar divergências na relação entre o indivíduo e os responsáveis pela instituição. Conseqüentemente, essas relações de tensão conduzirão os indivíduos rumo a diferentes estratégias identitárias, nas quais o processo de construção da identidade profissional não deverá ser identificado como resultado da soma de experiências individuais e coletivas, mas como um processo de reformulação e tentativas sucessivas de integração da atividade profissional.

Inúmeros estudos evidenciam que a profissão docente assume hoje, de maneira geral, sinais de precarização, gerando crises de identidade profissional associadas a péssimas condições de trabalho, a salários pouco atraentes, à não-valorização do profissional, além de outros problemas, ocasionando frustrações diante da atividade exercida, o que implica, certamente, impactos sobre as representações sobre a docência.
Se a construção da identidade profissional é também tarefa individual, ela está, porém, condicionada à estrutura social e histórica de cada contexto. Portanto, a profissão docente está em constante transformação, associada aos discursos que são apresentados pela mídia, pelo Estado, pelos movimentos sociais, pelas políticas públicas, entre outros, e que versam sobre a qualidade da escolarização, as novas práticas de ensino, as políticas educacionais, as condições de trabalho, a função social do professor e os programas de formação docente, bem como o processo de profissionalização. No que diz respeito à construção da identidade profissional de docentes, Gatti (1996) alerta para a necessidade de perceber a ação tanto dos sujeitos construtores quanto das circunstâncias em que tal construção ocorre.

Enfim, as convicções dos docentes, seus desejos, expectativas diante da atividade profissional, o repensar sobre as práticas pedagógicas, a formação docente, sua função social, experiências pessoais, constituem-se, também, em elementos que contribuem para a construção da identidade profissional. Esses elementos da subjetividade docente, por sua vez, estão marcados pelas experiências vividas pelos indivíduos ao longo de suas vidas, pelos discursos, pelas instituições e grupos aos quais tiveram acesso, participantes também da construção dos significados que esses docentes irão conferir às suas experiências em geral e à docência em particular.

Uma interessante sistematização da reflexão sobre os processos identitários é oferecida pelo antropólogo francês radicado no Brasil, Michel Agier, que descreve as abordagens da "antropologia das identidades": a) a abordagem contextual, que aponta para a inexistência de identidades em si mesmas, ressaltando seu caráter sempre referenciado em contextos, valores e interesses específicos que estão em jogo; b) a abordagem relacional, que busca o "abrigo virtual" da identidade, no sentido de identificar "o outro" com e contra o qual as identidades se afirmam, no sentido de que relacionamentos entre grupos "trabalham" alterando os referentes dos pertencimentos originais; c) a abordagem construtivista, que ressalta a identi- 
dade como algo "inventado", construído por seleções, escolhas e recomposições de elementos diversos (narrativas, mitos, valores, projetos), os quais são rearticulados de forma criativa e dinâmica, num "trabalho" de criação cultural; e, finalmente, d) a abordagem situacional das identidades, que conclama o pesquisador a atentar para "as interações e situações reais nas quais os atores se engajam [mais] do que nas representações formuladas a priori das culturas, tradições ou figuras ancestrais em nome das quais se supõe que eles agem" (Agier, 2001, p. 12). Somente a análise atenta dos contextos e das questões concretas em jogo nas situações de interação permite desvendar a lógica que perpassa os processos identitários.

Nossa investigação sobre a docência na educação profissional traz uma perspectiva interessante sobre tais reflexões, uma vez que permite evidenciar experiências, instituições, condições de trabalho dos entrevistados, que, por apresentarem particularidades, permitem evidenciar as relações entre estas e a construção de representações e identidades docentes, explicitando valores, projetos e concepções subjacentes aos significados conferidos à docência. Passamos então a analisar, ainda que de maneira breve, suas trajetórias anteriores ao magistério.

\section{Trajetórias anteriores ao magistério}

Praticamente a totalidade de nossos entrevistados é originária de famílias trabalhadoras, muitas delas numerosas, constituídas no interior do estado e que migraram para a Região Metropolitana de Belo Horizonte entre as décadas de 1950 e 1970, acompanhando o movimento econômico-demográfico mais geral de urbanização em todo o país. Chefiadas por pessoas analfabetas ou semi-alfabetizadas, essas famílias já possuíam, então, um projeto de escolarização dos filhos, a maioria das vezes pouco específico, ainda que algumas delas já vislumbrassem a necessidade de qualificação profissional para os novos ramos em expansão, notadamente o industrial. Apenas um dos pais ou mães desses professores possuía curso superior (odontologia), os demais eram operários semiqualificados da indústria metalúrgica ou da construção civil, barbeiros, militares de baixa patente, boiadeiros, funcionários públicos subalternos, enfermeiros. Quase todas as mães eram donas de casa, havendo, além dessas, uma babá, uma costureira, uma comerciante e uma artesã.

No interior dos projetos familiares de escolarização dos filhos, os cursos técnicos aparecem como ponto comum. Há vários casos em que a maioria dos irmãos dos entrevistados cursou o ensino técnico e, no caso dos nossos sujeitos, quase todos o fizeram. Isso indica estratégias familiares de inserção dos filhos no mercado em condições mais favoráveis, por cursos profissionalizantes. Mas, mesmo antes de ingressarem no ensino técnico, grande parte desses docentes já contribuía com a renda familiar desde os seus 10, 12 anos de idade, como pequenos vendedores, na maioria das vezes, ou como ajudantes dos pais. Muitos ressaltaram, de forma incisiva, o quão pobre foi sua infância, as privações e as dificuldades enfrentadas.

Quando eu iniciei o segundo grau, paralelo eu comecei a trabalhar. Eu tinha 15 anos, trabalhava numa prestadora de serviços como office-boy e ainda tinha que estudar no Colégio B, ali no centro. E eu trabalhava lá na Cidade Jardim, morando em Contagem. [...] E aí, quando eu estava completando 18 anos foi quando eu mudei totalmente a minha vida em função do falecimento do meu pai, e aí então eu fui para a Marinha, sempre morando em lugares diferentes e longe de casa. (Professor 4)

Em um dos relatos, a professora afirma, repetidas vezes, o sentimento de exclusão condicionado pela situação de pobreza na infância e pelo fato de ser negra. Esse sentimento a acompanha ao longo de sua trajetória de vida, só sendo amenizado após a conclusão do ensino superior e a inserção no mercado de trabalho como professora. Mesmo tendo sido entrevistados outros sujeitos afrodescendentes, essa questão não apareceu em outros depoimentos.

As experiências escolares aconteceram em escolas públicas. No geral, esses sujeitos estudaram as séries iniciais no interior e concluíram o então giná- 
sio na capital. As memórias do tempo de infância não são muito detalhadas, os depoimentos não se detêm muito sobre esse aspecto, priorizando a vida profissional. Pode-se perceber, todavia, o significado da infância pobre, com o trabalho já presente desde cedo em seu processo de socialização. Não aparecem memórias marcantes sobre professores ou escolas durante a infância, ainda que a maioria afirme que gostava da escola. Muitos consideram que eram "primeiros alunos" durante a infância, secundarizando os estudos quando do seu ingresso na adolescência, mas sem nunca terem sido maus alunos. A relação com a escola, se não é marcante, é positiva, caracterizada pelo sucesso - se pode-se chamar assim a baixa ocorrência de reprovações. Apenas um depoimento dá conta da presença de um sonho com o magistério desde cedo. A quase totalidade dos entrevistados nunca se havia colocado a possibilidade de seguir esse ofício; a perspectiva era de inserção numa área técnica e, para tanto, buscam cursos técnicos e, logo depois destes, a inserção no mercado de trabalho na área de formação, o que conseguem.

Mas a escola surge com uma enorme vitalidade nos depoimentos quando eles se referem aos cursos técnicos realizados. Alunos de instituições diversas (CEFET, SENAI, Escola Politécnica de Minas Gerais - POLIMIG, Colégio Técnico da Universidade Federal de Minas Gerais - COLTEC-UFMG, Rede Ferroviária Federal), todos ressaltam o valor de sua formação técnica. Há uma maior ênfase a esse fato nos casos de sujeitos que fizeram cursos de horário integral, como os do CEFET e do COLTEC. Os depoimentos dão conta, então, de vocações para áreas técnicas, em alguns casos verdadeiras paixões:

Eu tinha uma queda para a mecânica, isso era visível na minha vida, eu consegui perceber isso, a minha vocação, o gosto pela mecânica, eu percebi. [...] eu andava com a minha régua $\mathrm{T}$, desse tamanho, uma régua gigante, ela ia sempre comigo. (Professor 4)

Meu pai não aceitava de jeito nenhum que eu trabalhasse com mecânica, mas eu tinha um desejo enorme de trabalhar com automóvel, era paixão realmente por mecânica e manutenção de automóvel... (Professor 2)

Além da paixão pela área técnica, os cursos profissionalizantes também os marcaram pelas experiências ali vividas:

[...] ali mudou o meu caminho, que me tirou da rua, que com 14 anos eu tava estudando de manhã e à tarde, eu tava me mantendo ocupado, eu morei num bairro que eu vi colegas meus, um preso, outro morto, outro ainda traficando, eu passo e vejo e eu imagino só uma coisa: esta escola me tirou dali [...]. (Professor 13)

Esses professores apresentam-se como antigos bons alunos, destacando-se entre os colegas em suas trajetórias escolares. Alguns afirmam que essa característica é familiar. Há casos de professores que são os únicos da família a possuir curso superior. De qualquer maneira, os dados demonstram que esses docentes, ao longo de suas vidas, foram pessoas bastante disciplinadas, enfrentaram situações adversas, viveram - e ainda vivem - situações de extrema ocupação do tempo, além de terem conseguido gerenciar diversos reveses e lograr a conclusão de um curso superior e o ingresso numa profissão mais "leve" e intelectualizada que a maioria de seus amigos e irmãos.

Eu trabalhava no SENAC de auxiliar de escritório enquanto eu estudava na POLIMIG. E fiz o curso com muito sacrifício, andando a pé, muitas vezes, do Riacho, em Contagem, até o Centro, né? Pegando carona para economizar as passagens, andando a pé pelo menos até metade do caminho pra pegar um ônibus mais barato. Então, com todas essas dificuldades, eu dando aula particular, fazendo unhas, sem saber, eu cortava cabelo de homem e de mulher, então eu consegui formar [no curso técnico]. (Professor 16)

São comuns as falas que utilizam termos como "sucesso", "vitorioso", "consegui”, apontando para um olhar evolucionista com relação à sua própria história, ainda que, em termos da distribuição de renda nacional, quase todos se situem na faixa de renda abai- 
xo de cinco salários mínimos. Veremos, adiante, como esse "olhar" sobre a trajetória de um menino pobre "que teve sucesso na vida" será um dos elementos configuradores de uma identificação positiva com seus atuais alunos nos cursos técnicos.

Mesmo assim, aparecem algumas dificuldades vividas no âmbito escolar. A mais freqüente e curiosa é a avaliação, pelos entrevistados, de si mesmos, como extremamente tímidos e com dificuldades de expressão oral.

Eu era extremamente tímido, eu não tinha coragem de olhar para as pessoas, eu não tinha coragem de conversar com o público, em apresentações na escola eu tinha dificuldade demais de falar frente aos outros alunos. (Professor 3 )

Embora alunos aplicados e bem-sucedidos, pelo menos na educação básica e profissional, não tiveram na escola oportunidade de desenvolver habilidades de comunicação oral, o que demonstra, entre outras possíveis causas, falha significativa dos processos escolares vividos, em que não lograram superar a distância entre a linguagem popular adquirida na socialização primária e a norma culta adotada pela escola e outros espaços sociais.

Outra dificuldade relatada em algumas entrevistas refere-se ao fato de, sendo de origem popular, passarem a circular num meio freqüentado por pessoas de camadas médias. A questão do "choque cultural" é evidente, e aqueles então estudantes não possuíam referenciais que os ajudassem a lidar com essa questão:

Eu estudei graças à Mendes Pimentel [fundação da Universidade Federal de Minas Gerais de apoio aos estudantes carentes]. Mas eu tinha muito problema na escola, porque eu só convivi com filhinhos de papai, né? Dentro da Arquitetura, principalmente, então era um lugar que eu não me sentia muito bem [...] naquele meio eu me sentia muito diferente. (Professor 8)

Nessas condições eles ingressam no mercado de trabalho, agora como técnicos de nível médio. Depositam esperanças de alcançarem bons salários e de realizarem-se profissionalmente, mas o que encontram no mercado é bem diferente disso. Essas experiências terão um papel crucial na constituição futura de suas identidades docentes, o que se fará em contraposição às experiências na indústria ou em outros tipos de empresas.

$\mathrm{Na}$ indústria... o reconhecimento do profissional lá era difícil. O meu salário, de repente o meu salário na indústria era ruim. (Professor 11)

Se você trabalha na indústria, é pressão, é muita coisa, que você sai depois de nove horas e você sai cansadíssimo. Uma pressão que não acaba mais. Eles te dão um projeto pra fazer com o prazo de um mês pra terminar, chegou 15 dias e eles já te deixam louco: Como é que é? O projeto não tá pronto? É correria, mas correria mesmo, e o cara fica quase que nem um feitor, quase dando chicotada no pessoal pra poder fazer o projeto, a máquina, a tempo. [...] Você saía de lá mais velho, até! Quando eu saí de lá parece que eu tava saindo de uma prisão! (Professor 7)

As experiências no mundo do trabalho vão, com o tempo, dizendo qual o lugar do técnico ali, e este não parece ser muito compensador. Coelho (2003) mostra que os técnicos em geral investem na carreira técnica por cerca de cinco anos, quando percebem finalmente sua limitação, e partem, sempre que possível, para o curso superior, condição mínima exigida pelo mercado atual para ganhos acima de cinco salários mínimos. Também os nossos entrevistados, assim que aparece oportunidade de complementação de renda, seja ela qual for, agarram-na imediatamente. Muitos prestavam serviços técnicos como autônomos informais, desenvolvendo projetos à noite ou aos finais de semana. Alguns tentaram o comércio, outros foram para a pós-graduação e dali, então, para o magistério. A maioria ingressou na carreira docente de forma espontânea.

Provenientes de uma das trajetórias típicas nas camadas populares, ${ }^{3}$ esses sujeitos pareciam encami-

${ }^{3}$ Aqui nos referimos à trajetória de sucesso escolar no ensino fundamental, seguida pelo sucesso no ingresso em uma escola 
nhar-se para o mundo empresarial como técnicos de nível médio ou superior de áreas específicas. Entretanto, de forma bastante inesperada, surge a oportunidade, não prevista até então, de lecionarem.

Uma trajetória bastante diferenciada dessa é a daqueles que seguem um caminho acadêmico, ingressando na universidade logo após a conclusão do ensino técnico, ou passando muito rapidamente pelo mercado de trabalho e encaminhando-se para a pósgraduação logo depois de concluído o curso superior, ingressando no magistério depois disso ou concomitantemente à pós-graduação.

Uma trajetória menos típica foi encontrada em três depoimentos em que os entrevistados revelaram terem ingressado no ofício de professor logo após a conclusão do curso técnico. Em todos esses casos eles começaram a lecionar em escolas pequenas: um deles numa escola privada que oferta cursos de curta ou média duração, os outros dois em escolas comunitárias, sendo uma delas fundada por ex-dirigentes sindicais, a outra fundada como obra social de um exempresário muito bem-sucedido. Os dois últimos foram alunos das instituições onde lecionam e fizeram lá mesmo estágio, sendo, logo em seguida, convidados a lecionar. Assim como a maioria dos demais, esses professores nunca haviam cogitado transformarse em docentes, mas, uma vez experimentado o ofício, nunca mais o deixaram e deixam claro que o motivo principal para isso é ver a satisfação nos olhos dos alunos quando aprendem algo novo.

Apesar de possuírem experiências diferentes no que se refere a ter ou não passado por empresas com atividades técnicas, a grande maioria dirige-se ao magistério de forma inesperada, e ali permanece, se-

profissionalizante e, posteriormente, no mercado de trabalho como trabalhador qualificado. Uma outra trajetória típica nas camadas populares é a de insucesso escolar, quando os sujeitos abandonam a escola antes do término do ensino fundamental ou, quando o concluem, o fazem em condições tão precárias que inviabilizam o prosseguimento dos estudos em instituições onde haja processo seletivo para ingresso. gundo afirmam, principalmente pela alegria de ensinar - além de outros motivos como a remuneração e a flexibilidade de horários.

\section{Concepções sobre educação profissional}

Conforme já aponta a literatura, Nóvoa (1992), Gatti (1996), Dubar (1997), ficou patente durante o desenvolvimento da pesquisa que a história de vida dos entrevistados influencia na concepção que eles têm sobre educação e, no nosso caso, mais especificamente sobre educação profissional. Como já vimos anteriormente, nossos entrevistados têm trajetórias de vida semelhantes, ou seja, apesar das especificidades da vida pessoal, escolar, acadêmica e profissional de cada um, a maioria caracteriza-se por ser oriunda de famílias da classe trabalhadora; por ter feito curso técnico; por ter uma experiência profissional de trabalho em empresas ou em indústrias na sua área de formação inicial; por ter ido para a docência de maneira inesperada; por lecionar em cursos da educação profissional; por valorizar e sentir falta, mas nem sempre procurar uma formação pedagógica específica para o magistério. Tais aspectos de suas histórias de vida contribuíram para a construção de concepções particulares sobre educação, por eles apresentadas nas entrevistas.

Para melhor contextualizarmos o pensamento de nossos entrevistados em relação à função social da educação profissional, adotamos como pano de fundo do nosso referencial teórico os conceitos que a área acadêmica associa às expressões "educação técnica" e "educação tecnológica".

A literatura ${ }^{4}$ aponta que os significados desses termos implicam a presença de fortes concepções relacionadas a orientações político-pedagógicas subjacentes a distintos modelos de formação. Nesse caso,

${ }^{4}$ Para aprofundar no significado dos termos, ver as seguintes obras: Bastos (1997), Coelho (1997), Grinspun (2001), Laudares, Fiúza e Rocha (2005), Manfredi (2002) e Oliveira (2000). 
a expressão "educação técnica" estaria relacionada a uma formação ligada ao "saber fazer", preparando o trabalhador para "exercer suas capacidades laborativas" (Laudares, Fiúza \& Rocha, 2005, p. 62), ligada ao treinamento do trabalhador para exercer uma determinada profissão. Oliveira (2000, p. 41) aproxima o conceito de formação técnica "aos processos de treinamento do trabalhador no mero domínio das técnicas de execução de atividades e tarefas, no setor produtivo e de serviços". Por sua vez, a expressão “educação tecnológica" estaria associada a uma concepção ampla e universal de formação, buscando o desenvolvimento integral do trabalhador, priorizando a formação de uma consciência crítica, o domínio de princípios científicos e tecnológicos, o desenvolvimento das habilidades socioafetivas, cognitivas e éticas. Coelho (1997) observa:

O conceito de educação tecnológica possui uma abrangência maior, implicando uma formação que prevê o desenvolvimento integral do trabalhador, de suas amplas habilidades cognitivas - que incluem, mas ultrapassam a assimilação de informações técnicas, enfatizando o domínio dos fundamentos científicos subjacentes ao saber fazer, de suas habilidades sócio-afetivas, de sua ética e de uma reflexão sobre valores que incluam o estudo crítico do contexto sociopolítico e econômico em que a ciência e a tecnologia são produzidas, disseminadas e aplicadas (ou não). (p. 52)

Tendo tais concepções como referência, percebemos que os professores entrevistados têm uma visão de educação que ultrapassa o conceito de "educação técnica", mas que também não alcança todos os aspectos da "educação tecnológica". Muitos relacionam educação profissional à formação para o mercado de trabalho. Em suas falas, percebemos uma grande preocupação com questões como "transmissão dos conteúdos", "o posicionamento que o aluno enquanto profissional deverá ter no mercado de trabalho" e a "transmissão de conhecimentos práticos da profissão" adquiridos pelos professores durante o trabalho em empresas e/ou indústrias.
Porque eu sempre me preocupei com o meu nome. Porque chega um aluno ruim dentro de uma indústria para executar um trabalho e não sabe resolver nenhum problema técnico, não sabe ler um desenho, não sabe fazer dados... "Onde você estudou? Quem foi seu professor?", eu vou ficar morrendo de vergonha. (Professor 2)

Mas, ao mesmo tempo em que falam em formar o aluno para atender às demandas do mundo do trabalho, nossos entrevistados também valorizam questões como: saber pensar, construir atitudes, trabalhar a curiosidade, nortear a vida do aluno e trabalhar a auto-suficiência do aluno. Tais aspectos, além de extrapolarem o conceito de educação técnica, ainda ultrapassam a formação direcionada apenas para o mercado de trabalho, demonstrando que os professores também apresentam uma preocupação com uma formação mais ampla do aluno.

Bom, eu gosto de ser professor, de dar aula. Eu acho que é uma oportunidade muito bacana da gente contribuir... a gente acaba influenciando a vida de outras pessoas e é uma responsabilidade muito grande, né, porque você tem que influenciar positivament333e. [...] Então, é esse tipo de conceito que eu gosto de passar pra eles. Alguma coisa que está no momento, tipo política, alguma coisa que eu comento com eles, alguma coisa assim. (Professor 1)

Estamos preparando os alunos do [instituição de trabalho da professora entrevistada] pra ser agente transformador, a gente quer que eles tenham idéia, que eles gerem em si, que eles produzam, que eles dêem opinião, que eles modifiquem. Que eles sejam agentes de melhora do mundo, de alguma forma. (Professor 8)

Entretanto, observamos que aspectos como formação política, formação de um pensamento crítico e formação de uma consciência acerca das contradições do mundo do trabalho foram abordados por poucos professores, o que indica um limitado acesso deles a esse tipo de discussão em seus processos de formação inicial e continuada, e até em suas relações sociais mais amplas (limitada experiência em movimentos sociais e tipos de grupos de sociabilidade). 
Aspectos presentes na história de vida de nossos entrevistados, como a formação de técnico e a experiência de trabalho em empresas e/ou indústrias, além do ambiente de trabalho, contribuem fortemente para a construção de suas concepções sobre educação e para a definição dos aspectos prioritários a serem trabalhados na sala de aula da educação profissional. $O$ fato de eles priorizarem a formação de seus alunos para o mercado de trabalho parece relacionar-se com sua ampla experiência como técnicos que mantêm bem vivas as exigências feitas pelo mercado a esses profissionais. Em contrapartida, também percebem a necessidade de ir além dessa formação, especialmente aqueles com uma trajetória mais acadêmica (ingresso na universidade antes dos 30 anos, participação em atividades extracurriculares na universidade, realização de cursos de pós-graduação, notadamente stricto sensu).

Aqueles com maior experiência no mercado como técnicos acreditam que o aluno que sai de um curso técnico precisa dominar as especificidades da profissão para a qual se formou, saber adaptar-se e "sobreviver" ao ambiente de trabalho na indústria. Além disso, eles observam a necessidade de priorizar aspectos de formação para a vida pessoal dos alunos, mas esse segundo tipo de abordagem parece-nos ser menos recorrente, em virtude do tipo de formação e da trajetória desses professores. Como a maioria não tem formação pedagógica ou humanística, nem participou de organizações não-governamentais (ONGs) ou de movimentos sociais, eles não tiveram a oportunidade de se sensibilizar para essa perspectiva mais crítica da educação profissional.

\section{Outros espaços de socialização}

O professor, hoje, vê-se mergulhado em uma sociedade extremamente complexa, sendo, portanto, cada vez mais exigido em seu trabalho docente. Em entrevista ao Salto para o futuro da TVE, Nóvoa (2001) fala das novas atribuições e preocupações do professor na atualidade:

[...] a profissão docente sempre foi de grande complexida-

de. Hoje, os professores têm que lidar não só com alguns saberes, como era no passado, mas também com a tecnologia e com a complexidade social, o que não existia no passado. [...] e essa incerteza, muitas vezes, transforma o professor num profissional que vive numa situação amargurada, que vive numa situação difícil e complicada pela complexidade do seu trabalho, que é maior do que no passado.

Um dos problemas desse aumento de exigências é a limitação de tempo para que o professor invista em seus momentos de sociabilidade e lazer, tanto para se refazer do trabalho denso exigido pela profissão quanto para a sua diversão, participação social e/ou entretenimento.

Conforme Dumazedier (2001), o lazer engloba todas as ocupações que o indivíduo abraça de livre vontade para descanso, diversão, recreação ou formação desinteressada, incluindo a participação voluntária em atividades sociais, e ainda a criação livre, independente das obrigações profissionais, familiares e sociais.

Assumindo o lazer como importante espaço de formação humana e de equilíbrio pessoal do sujeito, constatamos, entretanto, que os professores dão pouca atenção aos momentos de lazer ou à sua ausência. Em contrapartida, nota-se uma grande preocupação com sua formação profissional. Dedicam o seu tempo livre a leituras técnicas, leituras que irão, segundo eles, agregar valor à sua profissão; e mesmo quando realizam leituras de textos literários, têm por objetivo a melhoria de seu desempenho profissional e social, como, por exemplo, a ampliação do vocabulário.

Li poucos livros que não fossem técnicos. A minha preocupação era a minha formação como profissional mesmo, sabe? (Professor 5)

[...] eu sou viciado em coisa técnica [...]. Mas eu preciso ler romance. Já li alguns romances quando eu era mais jovem. [...] Preciso. Você sabe por que que eu preciso? Pra aumentar minha cultura, é, como que se diz, pra eu falar melhor [risos], né? (Professor 6)

Esse dado sinaliza para a centralidade que o trabalho ocupa na vida desses profissionais e para a de- 
dicação permanente ao aprimoramento profissional, que limitam as atividades de seu cotidiano.

A participação desses professores em grupos sociais que extrapolem o mundo escolar ou empresarial é observada apenas em casos isolados. Assim como a leitura, a prática de esportes, quando é realizada, quase sempre em caráter esporádico, atende mais a uma necessidade de cuidados com a saúde do que como uma expressão de relaxamento, diversão e prazer. Porém, essa limitação das práticas culturais e de lazer, conforme Coelho (2003), precisa ser relativizada, evitando-se o risco de uma avaliação apressada e etnocêntrica de seu significado, pois pesquisas (Brandão, 2002) apontam que tal limitação é também observada em grupos profissionais das camadas médias, não se configurando como característica específica dos professores da educação profissional. Contudo, em todos os casos, os professores relataram apreciar atividades esportivas e culturais, e que não as praticam em virtude do fator tempo.

\section{Considerações finais}

Esse estudo permitiu, entre outros aspectos, ressaltar a história de vida como uma abordagem teóricometodológica privilegiada quando se pretende investigar a relação que os sujeitos estabelecem com o ofício - neste caso, a docência. Assim, corrobora-se a literatura que aponta os processos identitários docentes como resultado não apenas das experiências no campo do magistério, mas também das diversas dimensões que perpassam as trajetórias de vida desses sujeitos, os quais, em última instância, são aqueles que se apropriam das condições sociais disponíveis e criam as múltiplas possibilidades para o que é ser professor. Percebemos, no caso desses docentes, que o valor trabalho é referencial básico dessas construções identitárias, e que a docência permite a permanência desse valor - trabalho - entre esses trabalhadores qualificados, por meio de experiências que resgatam sua positividade, aparentemente perdida ou em crise em suas profissões de origem, identificadas como insalubres, repetitivas e opressoras. Os educadores entre- vistados, além de originarem-se das classes trabalhadoras, têm suas histórias de vida marcadas por uma formação técnica e pelo acúmulo de experiências anteriores no mercado de trabalho, bem típicas desse grupo. Em função disso, constroem uma auto-imagem de relativa ascensão social, o que também favorece para que confiram um significado todo particular ao ofício da docência.

Este estudo permitiu evidenciar que todo esse conjunto de experiências mencionadas (a origem popular, a referência no mundo do trabalho, a formação técnica, a importância secundária conferida ao lazer, a identificação com os alunos) possibilita a esses professores construir uma inserção na docência que é particular, diferente, em muitos aspectos, da observada entre docentes da educação geral. Enquanto vários estudos falam do "mal-estar docente" e apontam para o fenômeno do adoecimento, como no caso da doença de burnout, entre os docentes da educação básica, no caso da educação profissional os docentes estabelecem uma relação bastante positiva com essa atividade. Isso repercute de forma marcante na prática docente, naquilo que tais profissionais concebem como importante para a sua formação e a de seus alunos, além do próprio sentido conferido à docência.

A abordagem de história de vida mostra-se capaz de possibilitar o acesso do pesquisador às referências que orientam os sujeitos em sua construção de significados, favorecendo, por exemplo, o desvelamento dos aspectos contextuais, relacionais e construtivos da elaboração das identidades. Por essa razão, a positividade conferida à docência explica-se não pela assunção de um discurso "missionário", mas pelos aspectos bem concretos de contextos e relações vividos, aos quais esses sujeitos conferem significados por um "trabalho" ativo de construção de cultura e de realidades. Metodologias de abordagem sincrônica, ou que focam a investigação num único âmbito da existência, apesar de serem úteis no levantamento, por exemplo, das representações atuais sobre dada questão, não permitiriam, como a história de vida, captar o processo de construção de tais representações, e os elementos, nos campos de possibilidades 
dos sujeitos, que contribuíram para tais construções. Ao analisarmos trajetórias de diversos sujeitos que exercem hoje uma mesma atividade profissional, pudemos perceber especificidades em seus relatos, que, além de falar de cada um deles como sujeitos individuais, evidenciaram experiências curiosamente recorrentes que permitem captar alguns importantes aspectos sociais e culturais dos processos identitários desses docentes, explicitando formas particulares de experimentar a condição docente e apontando pistas para pensar políticas e práticas para sua formação inicial e continuada.

No caso da educação profissional, ficou evidenciado que as histórias de vida desses docentes constituem poderosas conexões que os aproximam de seus alunos. De origens sociais semelhantes, com experiências familiares e de vida bastante próximas, os docentes identificam os alunos, assim como a si mesmos, como "lutadores", à procura de uma oportunidade, e vêem, no mundo do trabalho, o principal (ou o possível) canal de acesso a melhores condições e vida. O magistério na educação profissional significa uma oportunidade de contribuir para a melhoria de vida de seus alunos, melhoria esta que é, na classe trabalhadora, valor central de orientação de vida. Sem dúvida, o caráter relativamente terminal da educação profissional também contribui para dar maior significado aos estudos aí empreendidos. O significado do trabalho docente consegue extrapolar, para esses sujeitos, sua dimensão meramente instrumental, e banha-se de sentidos expressivos, sentidos estes tão característicos das atuais demandas dos trabalhadores ao mundo do trabalho (Schuda, 2005). Além disso, embora seus ganhos financeiros não evidenciem uma significativa ascensão social, o fato de exercerem uma atividade não identificada como trabalho manual (de onde se originaram), em condições de trabalho menos insalubres do que na indústria, faz com que esses professores construam uma significação positiva para o magistério. Dessa forma, os processos identitários relacionados à docência mostram-se fortemente informados por espaços sociais outros, para além dos muros da escola, que articulam, numa teia de signifi- cados, hábitos e valores oriundos dessa diversidade de experiências.

Num momento em que se faz urgente a discussão e definição de uma política de formação inicial e continuada de professores para a educação profissional, inexistente no país, acreditamos que os impasses $\mathrm{e}$ as potencialidades vividas por esses docentes e aqui apontados possam constituir-se em pistas para a construção de tais políticas. Referimo-nos tanto ao reconhecimento, por um lado, do importante papel desempenhado pelos saberes do mundo do trabalho em sua constituição como docentes quanto, por outro lado, das importantes limitações impostas pela falta de acesso a um debate mais qualificado sobre a função social da escola e da educação profissional, informados pelo debate entre educação tecnológica, ensino técnico e formação humana.

\section{Referências bibliográficas}

AGIER, Michel. Distúrbios identitários em tempos de globalização. Mana, v. 7, n. 2, p. 7-33, 2001.

ANDRÉ, Marli Eliza Dalmazo de. Perspectivas atuais da pesquisa sobre docência. In: BUENO, Belmira; CATANI, Denice Bárbara; SOUSA, Cynthia Pereira de et al. Docência, memória e gênero: estudos sobre formação. São Paulo: Escrituras, 1997. p. 65-74.

BASTOS, João Augusto de Almeida. Fundamentos, características y perspectivas de la educación tecnológica. Boletin Cinterfor, n. 141, p. 7-28, out./dez. 1997.

BRANDÃO, Zaia. Elite's schooling in Brazil. In: CONGRESS OF INTERNATIONAL SOCIOLOGICAL ASSOCIATION, Brisben, 2002. Anais... Brisben: s.ed., 2002 (mimeo.).

COELHO, Suzana Lana Burnier. Repensando um projeto de educação tecnológica referenciado na formação do cidadão-técnico: algumas reflexões para a formulação de novas propostas educativas. Educação \& Tecnologia, Belo Horizonte, n. 2, p. 52-56, jul./ dez. 1997.

Visões de mundo e projetos de técnicos de nível médio. 2003. 278f. Tese (Doutorado Educação Brasileira) - Departamento de Educação, Pontifícia Universidade Católica do Rio de Janeiro, Rio de Janeiro, 2003.

DOMINICÉ. Pierre. L'histoire de vie comme processus de formation. Paris: Edition L'Harmattan, 1990. 
DUBAR, Claude. A socialização: construção das identidades sociais e profissionais. Porto: Porto Editora, 1997.

DUMAZEDIER, Joffre. Lazer e cultura popular. São Paulo: Perspectiva, 2001

FERRAROTTI, Franco. Sobre a autonomia do método biográfico. In: NÓVOA, António; FINGER, Matthias (Orgs.). O método (auto)biográfico e a formação. Lisboa: Ministério da Saúde. Depart. de Recursos Humanos da Saúde/Centro de Formação e Aperfeiçoamento Profissional, 1988. p. 17-34.

GATTI, Bernadete. Os professores e suas identidades: o desvelamento da heterogeneidade. Cadernos de pesquisa, São Paulo, n. 98 , p. 85-90, ago. 1996.

GOODSON, Ivor F. Dar voz ao professor: as histórias de vida dos professores e o seu desenvolvimento profissional. In: NÓVOA, António (Org.). Vidas de professores. Porto: Porto Editora, 1992. p. 63-78.

GRINSPUN, Mirian P. S. Zippin. Educação tecnológica: desafios e perspectivas. 2. ed. São Paulo: Cortez, 2001.

HALL, Stwart. A identidade cultural na pós-modernidade. Rio de Janeiro: DP\&A, 1999.

HELLER, Agnes. $O$ cotidiano e a história. 4. ed. Rio de Janeiro: Paz e Terra, 1992.

HUBERMAN, Michael. O ciclo de vida profissional dos professores. In: NÓVOA, António (Org.). Vidas de professores. Porto: Porto Editora, 1992.

KADDOURI, Mokhtar. Professionnalisation et dynamiques identitaires. In: SOREL, Maryvonne; WITTORSKI, Richard (Orgs.). La professionnalisation en actes et en questions. Paris: L'Harmattan, 2005. p. 145-157.

LAUDARES, João Bosco; FIÚZA, Jalmira Regina; ROCHA, Simone. Educação tecnológica: os impactos nos projetos pedagógicos dos cursos técnicos dos CEFETS Minas Gerais e Paraná pelos Decretos 2.208/97 e 5.154/04. In: ARANHA, Antônia Vitória; CUNHA, Daisy Moreira; LAUDARES, João Bosco (Orgs.). Diálogos sobre trabalho: perspectivas multidisciplinares. Campinas: Papirus, 2005. p. 57-90.

MANFREDI, Silvia Maria. Educação profissional no Brasil. São Paulo: Cortez, 2002.

NÓVOA, António. Os professores e as histórias da sua vida. In: NÓVOA, António (Org.). Vidas de professores. Porto: Porto Editora, 1992.

O professor pesquisador e reflexivo. TVE Brasil -

Salto para o futuro, Rio de Janeiro, 13 set. 2001. Disponível em:
<http://www.tvebrasil.com.br/SALTO/entrevistas/default.htm〉. Acesso em: 20 abr. 2006.

NUNES, Célia M. F.; CUNHA, Maria Amélia de A. A "escrita de si" como estratégia de formação continuada para docentes. Revista Espaço Acadêmico [online], n. 50, p. 11-23, jul. 2005. Disponível em: <http://www.espacoacademico.com.br/050/ 50pc_cunhanunes.htm>. Acesso em: 1 maio 2006.

OLIVEIRA, Maria Rita N. S. Mudanças no mundo do trabalho: acertos e desacertos na proposta curricular para o ensino médio (Resolução CNE 03/98). Diferenças entre formação técnica e formação tecnológica. Educação e Sociedade, Campinas, n. 70, p. 4062, abr. 2000.

QUEIROZ, Maria Isaura Pereira de. Relatos orais: do "indivizível" ao "dizível”. In: SIMPSON, Olga de Morais Von (Org.). Experimentos com histórias de vida (Itália-Brasil). São Paulo: Vértice, 1988. p. 14-43.

SANCHIS, Pierre. A crise dos paradigmas em antropologia. In: DAYRELL, Juarez (Org.). Múltiplos olhares sobre educação $e$ cultura. Belo Horizonte: Editora UFMG, 1996. p. 23-38.

SCHUDA, Sergio Ibañez. El trabajo visto por los jóvenes chilenos: un análisis de las representaciones sociales de los jóvenes urbano populares. Montevideo: Cineterfor/OIT, 2005.

VELHO, Gilberto. Projeto e metamorfose: antropologia das sociedades complexas. Rio de Janeiro: Zahar, 1994.

SUZANA BURNIER, doutora em educação pela Pontifícia Universidade Católica do Rio de Janeiro (PUC-Rio), é professora do Centro Federal de Educação Tecnológica de Minas Gerais, no qual exerce o cargo de diretora de graduação e coordena o curso de especialização Programa de Educação de Jovens e Adultos (PROEJA). Publicações recentes: Os significados do trabalho segundo técnicos de nível médio (Educação e Sociedade, Campinas, v. 27, n. 94, p. 153-174, 2006); Visões de mundo e projetos de trabalhadores qualificados de nível médio (Antropolítica, Niterói: EDUFF, v. 15, jul-dez, p. 83-97, 2004); MENGA, L.; BURNIER, Suzana L.; FELIPE, C.; CLEONICE, P.; LAURA, C. R. O professor e a pesquisa (4. ed. Campinas: Papirus, 2006); O mundo do trabalho e a construção cultural de projetos de homem entre jovens favelados (In: DAYRELL, Juarez (Org.). Múltiplos olhares sobre educação e cultura. Belo Horizonte: Editora da UFMG, 2006. p. 137-165). Pesquisa em andamento: "A formação de professores para o ensino técnico", com financiamento do Conselho Nacional de Desenvolvimento Científico e Tecnológico (CNPq) e da Fun- 
dação de Amparo à Pesquisa do Estado de Minas Gerais (FAPEMIG).

E-mail: suzana@des.cefetmg.br

MARINA NUNES DURÃES, mestre em educação tecnológica pelo CEFET-MG, atualmente leciona no Instituto Superior de Educação Anísio Teixeira da Fundação Helena Antipoff, trabalhando com formação de professores. Publicações recentes: Docentes da educação profissional: concepções acerca desta modalidade de ensino (In: ENCONTRO INTERNACIONAL DE POLÍTICAS EDUCACIONAIS E FORMAÇÃO DE PROFESSORES DA AMÉRICA LATINA E DO CARIBE, 1., Juiz de Fora: UFJF, 2006); Concepções de docentes da educação profissional frente ao debate entre educação técnica e educação tecnológica. (In: SEMINÁRIO DE PROGRESSO EM PESQUISA EM PÓSGRADUAÇÃO, 7., e ENCONTRO INTERINSTITUCIONAL DE PESQUISAEM PÓS-GRADUAÇÃO, 2., Belo Horizonte: CEFETMG, 2005. Caderno de Resumos da I Semana de Ciência e Tecnologia do Cefet-MG, 2005). Pesquisa em andamento: "Vidas de professores da educação profissional”.E-mail: marinand@uai.com.br

REGINA MARA RIBEIRO CRUZ, especialista em informática aplicada à educação, mestranda em educação tecnológica pelo CEFET-MG, é professora no Instituto Superior de Educação Anísio Teixeira da Fundação Helena Antipoff. Pesquisa em andamento: "Vidas de professores da educação profissional". E-mail: profreginacruz@yahoo.com.br

MÔNICA LANA PAZ, mestranda em educação tecnológica pelo CEFET-MG, é professora da rede municipal de Contagem. Publicações recentes: A construção da identidade profissional de professores de matemática. O caso dos egressos do Programa Especial de Formação Docente do CEFET-MG (In: SIMPÓSIO TRABALHO E EDUCAÇÃO, 3., Belo Horizonte: FaE/UFMG, 2005);
PAZ, M. L.; TOMASI, A. P. N.; SILVA, I. M. M. A docência na educação profissional: reflexões sobre a formação docente e a importância da licenciatura. (In: ENCONTRO INTERNACIONAL DE POLÍTICAS EDUCACIONAIS E FORMAÇÃO DE PROFESSORES DA AMÉRICA LATINA E DO CARIBE, 1., Juiz de Fora: UFJF, 2006). Pesquisa em andamento: "Vidas de professores da educação profissional”. E-mail: monykynhalana@yahoo.com.br

ADRIANA NETTO SILVA, mestranda em educação tecnológica pelo CEFET-MG. Publicações recentes: BURNIER, Suzana L.; CRUZ, Regina M. R.; DURÃES, Marina. N.; MENDES SILVA, Ivone M.; PAZ, Mônica L.; SILVA, Adriana. N. Histórias de vida de professores: o caso da educação profissional (In: CONGRESSO INTERNACIONAL SOBRE PESQUISA (AUTO)BIOGRÁFICA, 2., Salvador: EDUNEB, 2006). Pesquisa em andamento: "Vidas de professores da educação profissional”. E-mail: dricanettos@gmail.com

IVONE MARIA MENDES SILVA, psicóloga e mestranda em educação tecnológica pelo CEFET-MG. Publicações recentes: MENDES SILVA, Ivone M.; TOMASI, Antônio P. N.; PAZ, Mônica L. A docência na educação profissional: reflexões sobre a formação docente e a importância da licenciatura (In: ENCONTRO INTERNACIONAL DE POLÍTICAS EDUCACIONAIS E FORMAÇÃO DE PROFESSORES DA AMÉRICA LATINA E DO CARIBE, 1., Juiz de Fora: UFJF, 2006); MENDES SILVA, Ivone M. E os jovens, como pensam o trabalho na contemporaneidade: significados do trabalho para a juventude no Brasil (In: SIMPÓSIO TRABALHO E EDUCAÇÃO, 3., Belo Horizonte: FaE/UFMG, 2005). Pesquisa em andamento: "Vidas de professores da educação profissional”. E-mail: ivesilva@yahoo.com.br

Recebido em novembro de 2006 Aprovado em março de 2007 